\title{
Imaging of the common bile duct in patients undergoing laparoscopic cholecystectomy
}

\author{
P J Hainsworth, M Rhodes, R H K Gompertz, C P Armstrong, T W J Lennard
}

\begin{abstract}
Options for managing the common bile duct during laparoscopic cholecystectomy include routine peroperative cholangiography and selected preoperative endoscopic retrograde cholangiopancreatography (ERCP). The use of these methods was reviewed in 350 patients with symptomatic gall stones referred for laparoscopic cholecystectomy. Unit A $(n=114)$ performed routine cystic duct cholangiography but undertook preoperative ERCP in patients at very high risk of duct stones only; unit $B$ $(n=236)$ performed selected preoperative ERCP on the basis of known risk factors for duct stones. The detection rate for common bile duct stones was similar for units $A$ and $B(16 \% v 20 \%)$. In unit $A$, five of seven patients who had preoperative ERCP had duct stones. Operative cholangiography was technically successful in $90 \%$ of patients and duct stones were confidently identified in 13 , one of whom went on to immediate open duct exploration. Postoperative ERCP identified duct stones in only four patients, indicating spontaneous passage in eight. In unit B, preoperative ERCP was undertaken in $\mathbf{7 6}$ of $236(32 \%)$ patients and duct stones were identified in $47(20 \%)$. Duct clearance was successful in $42(18 \%)$ but failed in five $(2 \%)$, necessitating elective open duct exploration. Both protocols for imaging the common bile duct worked well and yielded satisfactory short term results. (Gut 1994; 35: 991-995)
\end{abstract}

For patients undergoing laparoscopic cholecystectomy, there is controversy about the timing and method of imaging the common bile duct and subsequent treatment of common bile duct stones. During open cholecystectomy, surveys show that most surgeons favour routine cholangiography. ${ }^{12}$ With the advent of laparoscopic cholecystectomy, a shift in practice has occurred, with only $15-30 \%$ of surgeons in Europe and America now performing routine peroperative cholangiography. ${ }^{3-6}$

Most agree that preliminary peroperative cholangiography helps avoid false negative common bile duct explorations and that cholangiography related complications are rare. ${ }^{78}$ However, peroperative cholangiography adds about 20 minutes to the laparoscopic procedure. ${ }^{9-11}$ Much more contentious questions are firstly, does routine peroperative cholangiography prevent serious duct injury and, secondly, does selective omission lead to the retention of clinically important common bile duct stones? Many suspect an increase in serious duct injuries since the widespread introduction of laparoscopic cholecystectomy. ${ }^{12} 13$ These injuries mainly seem to occur while the surgeon is relatively inexperienced ${ }^{5614}$ and their number may be increased with laser dissection. ${ }^{15}$ Routine peroperative cholangiography shows unsuspected common bile duct stones in $0-12 \%$ patients undergoing elective cholecystectomy. ${ }^{7}$ 9 16-19 While selective cholangiography overlooks these stones, the long term natural history of the 'silent' stone is unclear. ${ }^{20}$

Laparoscopic cholecystectomy has focussed attention on the timing and method of imaging the bile duct. Preoperative endoscopic rectrograde cholangio-pancreatography (ERCP) is an alternative to peroperative cholangiography which also allows the removal of common bile duct stones. ERCP is too dangerous and expensive for screening every patient who undergoes laparoscopic cholecystectomy and has to be used selectively. ${ }^{20}$ Stone clearance at ERCP is successful in about $85 \%$ of patients, although several attempts may be required. ${ }^{21}$ If preoperative papillotomy and stone extraction fails, the option of duct exploration at the time of cholecystectomy remains.

This paper compares the experience of two centres, one espousing routine cystic duct cholangiography with postoperative ERCP for retained stones, the other following a policy of selected preoperative ERCP and stone extraction.

\section{Patients and methods}

When laparoscopic cholecystectomy was introduced in both hospitals in 1990, protocols for the management of patients with gall stones were defined. Both elective and emergency procedures were included on both units. An 'all comers' policy was adopted for those undergoing elective surgery. The policy for emergency admissions with acute cholecystitis or biliary colic differed between the units. Those in unit A were managed conservatively and interval laparoscopic cholecystectomy was performed at about six weeks. In unit B, patients were placed on the next available operating list, which might or might not have been during the same admission. On both units, patients presenting with jaundice, acute pancreatitis, or ascending cholangitis were submitted to laparoscopic cholecystectomy after they had recovered from their acute illness. The standard method of diagnosing gall stones was an ultrasound scan. Liver function tests were regarded as 'obstructive' if the serum alkaline phosphatase or serum bilirubin, 
TABLE I Clinical features of patients referred for laparoscopic cholecystectomy

\begin{tabular}{lcc}
\hline Features & Unit $A(n=114)$ & Unit $B(n=236)$ \\
\hline Age (y), median (range) & $52(21-88)$ & $48(16-91)$ \\
Sex (\%): & $14(12)$ & $55(23)$ \\
Men & $100(88)$ & $181(77)$ \\
$\quad$ Women & $113(99)$ & $186(79)$ \\
Mode of admission (\%): & $1(1)$ & $50(21)$ \\
Elective & & \\
Emergency & $93(82)$ & $130(55)$ \\
Principle indication (\%): & & \\
Biliary colic & $1(1)$ & $7(3)$ \\
Acute cholecystitis & $11(10)$ & $56(24)$ \\
$\quad$ Operated $\leqslant 10 \mathrm{~d}$ & $2(2)$ & $31(13)$ \\
$\quad$ Operated >10 d & $4(4)$ & $12(5)$ \\
Jundice $\dagger$ & $3(3)$ & $0(0)$ \\
Acute pancreatitis $\dagger$ & & \\
Cholangitis $\dagger$ &
\end{tabular}

*Includes those initially admitted as an emergency in whom surgery was deferred. †Operated after acute illness.

or both, were above the normal range of the laboratory.

In unit A, preoperative ERCP was restricted to those deemed to be at very high risk of common bile duct stones. Cystic duct cholangiography using image intensification ${ }^{22}$ was attempted in all patients, except where a preoperative sphincterotomy had been performed. If common bile duct stones were detected, and providing these looked as if they could be safely retrieved at ERCP, this was undertaken postoperatively. In unit B, selected preoperative ERCP was performed on the basis of a history of jaundice or pancreatitis, abnormal liver function tests, and ultrasound evidence of common bile duct stones or a dilated common bile duct. Cholecystectomy was performed on the next available list and peroperative cholangiography was undertaken only to help define uncertain anatomy.

The records for all patients undergoing laparoscopic cholecystectomy between October 1990 and July 1992 were studied retrospectively. This period covers the first experience with laparoscopic cholecystectomy at both hospitals. Follow up was by routine outpatient appointment at unit $A$ and by the general practitioner at unit $B$. The ability of the various methods used to predict common bile duct stones in this study - that is, history, biochemistry, and bile duct diameter - were investigated using the sensitivity (proportion of patients with common bile duct stones correctly

TABLE II Preoperative prediction of common bile duct (CBD) stones *

\begin{tabular}{|c|c|c|c|c|}
\hline & \multicolumn{2}{|c|}{ Unit $A(n=114)$} & \multicolumn{2}{|c|}{ Unit $B(n=236)$} \\
\hline & $\begin{array}{l}\text { No of } \\
\text { patients }\end{array}$ & $\begin{array}{l}\text { No with } \\
\text { stones }\end{array}$ & $\begin{array}{l}\text { No of } \\
\text { patients }\end{array}$ & $\begin{array}{l}\text { No with } \\
\text { stones }\end{array}$ \\
\hline \multicolumn{5}{|l|}{ History: } \\
\hline Jaundice & 2 & 2 & 31 & 27 \\
\hline Past jaundice & 4 & 1 & 11 & 4 \\
\hline Pancreatitis & 5 & 0 & 14 & 5 \\
\hline Cholangitis & 2 & 2 & 0 & 0 \\
\hline No history & 101 & 13 & 180 & 11 \\
\hline \multicolumn{5}{|c|}{ Liver function tests (LFTs): } \\
\hline Obstructive & 13 & 4 & 53 & 32 \\
\hline Normal & 101 & 14 & 183 & 15 \\
\hline \multicolumn{5}{|c|}{ CBD ultrasound findings (USS): } \\
\hline Dilated & 5 & 2 & 45 & 38 \\
\hline Not dilated & 109 & 16 & 191 & 9 \\
\hline \multicolumn{5}{|c|}{ Combined history, LFTs and USS: } \\
\hline High risk stones & 25 & 10 & 81 & 47 \\
\hline Low risk stones & 89 & 8 & 155 & 0 \\
\hline
\end{tabular}

-Refers to only those stones discovered at ERCP or peroperative cholangiography. †At the time of preoperative ERCP. identified by the test), specificity (proportion without stones correctly identified), positive predictive value (proportion of patients with positive test results correctly diagnosed), and the negative predictive value (proportion with negative test results correctly diagnosed) for these methods, both singly and in combination.

\section{Results}

During the 22 month study period, laparoscopic cholecystectomy was attempted in 114 consecutive patients with symptomatic gall stones in unit A. Unit B attempted laparoscopic cholecystectomy in 231 consecutive patients with gall stones; five other patients were electively submitted to open surgery because duct stones could not be cleared at preoperative ERCP and papillotomy. The patient characteristics and indications for surgery for the two groups are shown in Table I. The apparent lack of emergency admissions for unit A reflects the unit's preference for interval cholecystectomy after acute admissions.

The overall detection rates for common bile duct stones in patients undergoing laparoscopic cholecystectomy in units A and B were 18 of $114(16 \%)$ and 47 of $236(20 \%)$ respectively. In unit A, stones were detected at preoperative ERCP in five of $114(4 \%)$ patients and at peroperative cholangiography in 13 of $114(11 \%)$. In unit $\mathbf{B}$, stone detection was by preoperative ERCP. The various methods used to predict common bile duct stones in this study - that is, history, biochemistry, and bile duct diameter are summarised in Table II. In unit A, the combination of history, liver function tests, and ultrasound predicted duct stones with a sensitivity, specificity, positive predictive value, and negative predictive value of $0.56,0.84,0.40$, and 0.91 respectively. In unit $B$, this combination of factors was actually used to select patients for ERCP, and no stones were detected by other means.

Preoperative ERCP was performed in seven of $114(6 \%)$ patients in unit $A$, because of persistent jaundice $(n=2)$, a dilated common bile duct $(n=1)$, and 'obstructive' liver function tests $(n=4)$. Duct stones were confirmed and successfully extracted in five patients, requiring two ERCPs in one case. In unit B, preoperative ERCP was undertaken in 76 of $236(32 \%)$ potential candidates for laparoscopic cholecystectomy. Indications included jaundice $(n=31)$, previous jaundice $(n=11)$, pancreatitis $(n=14)$, 'obstructive' liver function tests $(n=9)$, and a dilated common bile duct $(n=14)$ (Table II). Common bile duct stones were identified in 47 of $76(62 \%)$. More than one ERCP was required in 21 patients. Duct stones were successfully extracted in 42 , leaving five patients with retained stones who were submitted to open surgery.

Peroperative cholangiography was attempted in 109 of 114 patients in unit A - two after conversion to an open procedure. Laparoscopic peroperative cholangiography failed in 10 cases because of inability to cannulate a narrow cystic 
TABLE III Features of common bile duct (CBD) stones discovered at laparoscopic cholangiography (POC) in unit $A$

\begin{tabular}{rllllll}
\hline & \multicolumn{3}{l}{ POC findings } & & & \\
\cline { 2 - 4 } $\begin{array}{rllll}\text { Case } \\
\text { No }\end{array}$ & $\begin{array}{l}\text { Size } C B D \\
\text { stones }(\mathrm{mm})\end{array}$ & $\begin{array}{l}\text { No of } \\
\text { CBD stones }\end{array}$ & $\begin{array}{l}\text { CBD } \\
\text { dilated }\end{array}$ & $\begin{array}{l}\text { Predicted } \\
\text { preoperatively }\end{array}$ & $\begin{array}{l}\text { Postoperative } \\
\text { ERCP } \\
\text { findings }\end{array}$ \\
\hline 1 & 5 & 1 & Yes & Yes & Passed \\
2 & 8 & 1 & No & No & Passed \\
3 & 6 & 1 & No & No & Passed \\
4 & 6 & 5 & No & No & Extracted \\
5 & 7 & 3 & No & No & Passed \\
6 & 5 & 1 & No & No & Passed \\
7 & 5 & 1 & Yes & No & Extracted \\
8 & 4 & 1 & No & No & Passed \\
9 & 7 & 4 & No & Yos & Passed \\
10 & 6 & 1 & No & Yes & Extracted \\
11 & 11 & 6 & Yes & Yes & Extracted \\
12 & 6 & 1 & & & \\
\hline
\end{tabular}

^Predicted by history, biochemistry, or ultrasound scan.

duct, and in one instance because the image intensifier malfunctioned. Normal cholangiograms were obtained in 84 of 98 patients. Laparoscopic peroperative cholangiography showed common bile duct stones in 12 patients and a previously unsuspected common bile duct injury in one patient where there was no proximal filling, allowing immediate repair. Open peroperative cholangiography detected common bile duct stones in a further patient, dealt with by duct exploration. The twelve patients with stones detected at laparoscopic peroperative cholangiography underwent ERCP between four and 96 days after surgery, with two attempts required in one patient. Duct stones were found and successfully extracted in four of 12 patients, indicating spontaneous passage in eight of 12 .

Of the 89 patients who were not suspected of harbouring common bile duct stones (Table II), eight were confidently shown to have duct stones at peroperative cholangiography. At subsequent ERCP, the stones had already passed in six and were extracted in two. Only two of four patients who needed postoperative ERCP stone removal were predicted on the basis of history, biochemistry, or bile duct diameter (Table III). For those found to have common bile duct stones at laparoscopic peroperative cholangiography, there was little correlation between the size or number of stones and subsequent spontaneous passage (Table III).

TABLE IV Complications of laparoscopic cholecystectomy and ERCP

\begin{tabular}{|c|c|c|}
\hline & $\begin{array}{l}\text { Unit } A \\
(n=114)\end{array}$ & $\begin{array}{l}\text { Unit B } \\
(n=236)\end{array}$ \\
\hline \multicolumn{3}{|l|}{ Major complications (\%): } \\
\hline Common bile duct injury & $1(0 \cdot 9)$ & 0 \\
\hline \multicolumn{3}{|l|}{ Peritoneal collection: } \\
\hline Laparotomy ${ }^{\star}$ & 0 & $1(0 \cdot 4)$ \\
\hline Percutaneous drain & $1(0.9)$ & \\
\hline Intestinal obstruction $†$ & & $1(0.4)$ \\
\hline Brachial plexus injury & $1(0.9)$ & 0 \\
\hline \multicolumn{3}{|l|}{ Minor complications (\%): } \\
\hline Hyperamylasaemia after ERCP & $2(1 \cdot 8)$ & $2(0 \cdot 8)$ \\
\hline Wound infection & $1(1 \cdot 8)$ & \\
\hline Incisional hernia & 0 & $1(0.4)$ \\
\hline Chest infection & 0 & $2(0 \cdot 8)$ \\
\hline \multicolumn{3}{|l|}{ Deaths $(\%)$ : } \\
\hline Bacterial endocarditis & $1(1 \cdot 8)$ & 0 \\
\hline Readmissions (\%): & & \\
\hline Abdominal pain & $1(1 \cdot 8)$ & $3(1 \cdot 3)$ \\
\hline
\end{tabular}

^Cystic stump leak demonstrated at ERCP. †Meckel's band. $¥$ Temporary neuropraxia related to position of arm in patient requiring hepaticojejunostomy for common bile duct injury.
Seven patients in unit A (6\%) were converted to an open cholecystectomy, six because of difficulty in displaying the anatomy and one after peroperative cholangiography showed a duct injury. In unit B only three patients were converted for technical reasons, although five others were selected for open cholecystectomy on the basis of the preoperative ERCP, giving an open operation rate of 3\%. The complications are shown in Table IV. There were no complications attributable to peroperative cholangiography. To date, only one postoperative ERCP has been performed in unit $B$, and this was for a cystic stump bile leak which eventually required open drainage. Hyperamylasaemia with abdominal pain complicated ERCP in two patients in each unit. There were no life-threatening complications from ERCP. The only unexpected readmission to unit A was a patient (case 9, Table III) who developed pain and clearly passed her stone while awaiting an ERCP. Three patients were readmitted to unit B within seven days for unexplained abdominal pain for which no cause was found.

\section{Discussion}

Because this is a non-randomised, unmatched study, care must be exercised in making comparisons between the groups. Nevertheless, most surgeons who perform laparoscopic cholecystectomy currently adopt one or other of the cholangiography policies represented in this study and, as yet, there are no prospective, randomised series on which to base opinion.

The incidence of common bile duct stones has been reported to be lower for laparoscopic cholecystectomy $(<2 \%)$ than open cholecystectomy (13-20\%), ${ }^{23}$ presumably reflecting lower detection rates and possible selection bias. One large post mortem study indicated that $24 \%$ of adults with gall bladder stones had stones elsewhere in the biliary tree. ${ }^{24}$ In our series, common bile duct stones were identified in $18.6 \%$ patients referred for laparoscopic cholecystectomy. In unit $\mathrm{A}$, cholangiography (ERCP or peroperative cholangiography) was undertaken in $89 \%$ of patients, and identified common bile duct stones in $16 \%$. Stones were subsequently confirmed in only $9 \%$ patients, suggesting spontaneous passage while awaiting postoperative ERCP in $7 \%$. We do not believe that these represent air bubbles since dynamic $\mathrm{C}$-arm image intensification was used. In unit B, ERCP was performed in $32 \%$ patients referred for laparoscopic cholecystectomy, and common bile duct stones were detected in $20 \%$. If patients with overt jaundice at the time of presentation are excluded, the detection rate for common bile duct stones is $14 \%$ (16 of $112)$ and $10 \%$ (20 of 205) for units $A$ and $B$. Whether or not any bile ducts which were not imaged contained duct stones is speculative.

Most cholangiography series report unsuspected duct stones in $2-12 \%$ patients. Various predictors for common bile duct stones have been proposed, including a history of jaundice, pancreatitis or cholangitis, biochemical abnormalities and ultrasound evidence of a dilated duct, common bile duct stones, or multiple 
gall bladder stones. The data from unit A indicate that the combination of history, liver function tests, and ultrasound detects only $56 \%$ of common bile duct stones (Table II). In patients thought to be at 'high risk' of common bile duct stones, only $40 \%$ had stones, and in patients at 'low risk', 9\% had unsuspected stones. In unit B, this combination of factors was actually used to select patients for ERCP, hence a sensitivity of $100 \%$ and a negative predictive value of $100 \%$. Nevertheless, no unit B patient thought to be at 'low risk' of duct stones has yet presented with duct stones.

Selective cholangiography misses a proportion of common bile duct stones, but does this matter? Several authors have pointed out that very few, if any, clinically significant stones subsequently present in those submitted to selective cholangiography. ${ }^{17} 1925-29$ What becomes of silent stones? The possibilities are spontaneous passage, continued silence, or delayed presentation.

That stones may pass spontaneously is well recognised in the context of acute pancreatitis. ${ }^{30} 31$ It has been suggested that since asymptomatic gall bladder calculi may not cause clinical problems, stones may also remain the common bile duct without complication. ${ }^{20}$ However, follow up in series of cholecystectomy patients has generally been short. Thurston and McDougal described 91 patients who presented with common bile duct stones after cholecystectomy, $26 \%$ of whom did so 10 years after their initial surgery. ${ }^{32}$ Johnson and Hosking suggested that 15-25\% of those with retained common bile duct stones after cholecystectomy develop serious complications. ${ }^{33}$ The experience of unit A is that unsuspected duct stones often pass spontaneously; only two of eight cases required papillotomy and stone removal. It should be noted, however, that of four patients requiring endoscopic stone extraction, two were unpredicted. Thus, if cholangiography is omitted, approximately $2 \%$ of patients would be expected to harbour common bile duct stones not otherwise forecast. Whether any sequelae would arise from leaving such stones behind remains conjectural.

Considerable difference of opinion exists concerning the ability of peroperative cholangiography to prevent duct injury, with occasional reports of peroperative cholangiography itself causing damage to the cystic duct stump or common bile duct. ${ }^{1834}$ Sceptics maintain that damage usually occurs either before the procedure or while awaiting development of the films. ${ }^{35}$ Even when a normal cholangiogram is obtained, damage may occur through thermal injury or inaccurate clip placement. ${ }^{1415}$ Nevertheless, peroperative cholangiography may occasionally allow. prevention of injury ${ }^{36}$ or at least early recognition and immediate repair. ${ }^{34}$ In patients with common bile duct injuries referred for treatment after laparoscopic cholecystectomy, peroperative cholangiography was usually omitted. ${ }^{14} 15$ This study does not support routine peroperative cholangiography as a means of preventing duct injury, since no such injuries occurred in unit B. However, in a few patients, peroperative cholangiography allowed confirmation of the anatomy and prevented the need to convert to an open operation. Furthermore, the one duct injury which occurred in this series was recognised as a result of an abnormal cholangiogram, allowing immediate repair with a favourable outcome.

Reliance on selected preoperative ERCP as a means of diagnosing bile duct stones has the disadvantage of being required in a large proportion of patients $-32 \%$ in unit B in our series. Furthermore, ERCP was normal in 29 of $76(38 \%)$ patients, and was therefore an unnecessary risk and expense. The routine use of preoperative intravenous cholangiography might reduce the number of negative ERCPs. Although popular in France, ${ }^{3}$ infusion cholangiography is not widely used in this country because of perceived limitations in image quality and the small risk of adverse reactions. Nevertheless, careful comparisons with operative cholangiography have shown that reasonable diagnostic accuracy can be achieved with scope for reducing the number of direct (endoscopic or operative) cholangiograms. ${ }^{37} 38$

The method and timing of cholangiography depend partly on the subsequent approach to managing common bile duct stones. The options are (i) preoperative ERCP with stone extraction, (ii) peroperative cholangiography with open exploration of the duct, (iii) peroperative cholangiography with delayed ERCP, and (iv) peroperative cholangiography with laparoscopic exploration of the duct which, currently, is not widely practiced. As discussed above, preoperative ERCP had the disadvantage in our series of being required in a large number of patients (76 of 236) with multiple attempts needed in 21 of $236(9 \%)$. The risk of sphincterotomy was only incurred, however, in those with common bile duct stones. Deferring the removal of stones until the time of postoperative ERCP carries the potential risks of cystic stump leakage and failure to extract the stone at ERCP, although neither features in reported series. In deciding between immediate open exploration and ERCP with sphincterotomy, the risk of exploration is much less than that of ERCP in younger, fitter patients but rises and reverses above the age of $60 .{ }^{34}$

In our series, both protocols for imaging and treating the common bile duct achieved good results, and our data do not allow us to recommend one policy above the other. Both approaches demand specialist imaging facilities and incur expensive overheads, and choice will be influenced by local resources and available technical skills. In the future, the continued development of laparoscopic bile duct exploration may influence practice. At present, however, the controversy seems set to continue.

This paper was read at American Gastroenterological Association Annual Scientific Meeting, Boston, MS, 15-21 May 1993 and the abstract was published in Gastroenterology 1993; 104: A363. 
1 DenBeston L, Berci G. The current status of biliary tract surgery: an international study of 1072 consecutive patients. World $\mathcal{F}$ Surg 1986; 10: 116-22.

2 Cahill CJ, Pain JA. Current practice in biliary surgery. $\mathrm{Br} \mathfrak{F}$ Surg 1988; 75: 1169-72.

3 Cushieri A, Dubois F, Mouiel J, Mouret P, Becker H, Buess $\mathrm{G}$, et al. The European experience with laparoscopic cholecystectomy. Am $\mathcal{F}$ Surg 1991; 161: 385-7.

4 Macintyre IMC, Wilson RG. Impact of laparoscopic cholecystectomy in the UK: a survey of consultants. Br f Surg 1993; 80: 346 .

5 The Southern Surgeons Club. A prospective analysis of 1518 laparoscopic cholecystectomies. N Engl f Med 1991; 324: 1073-8.

6 Deziel DJ, Millikan KW, Economou SG, Doolas A, Ko S-T, Airan MC. Complications of laparoscopic cholecystetomy: a national survey of 4292 hospitals and an analysis of 77604 cases. Am F Surg 1993; 165: 9-14.

7 Shively EH, Wieman TJ, Adams AL, Romines RB, Garrison RN. Operative cholangiography. Am f Surg 1990; 159: 380-5.

8 Hunter JG. Avoidance of bile duct injury during laparoscopic cholecystectomy. Am f Surg 1991; 162: 71-6.

9 Flowers JL, Zucker KA, Scott MG, Scovill WA, Imbembo AL, Bailey RW. Laparoscopic cholangiography. Ann Surg 1992; 215: 209-16.

10 Paterson-Brown S, Garden OJ. Bile duct stones and laparoscopic cholecystectomy [Letter]. $B M F$ 1992; 303: 1475.

11 Nathanson LK, Shimi S, Cushieri A. Laparoscopic cholecystectomy: the Dundee technique. Br F Surg 1991; 78: $155-9$

12 Macintyre IMC, Wilson RG. Laparoscopic cholecystectomy. $B r \mathcal{F}$ Surg 1993; 80: 552-9.

13 Phillips EH. Routine versus selective intraoperative cholangiography. Am ₹ Surg 1993; 165: 505-7.

14 Davidoff AM, Pappas TN, Murray EA, Hillern DJ, Johnson $\mathrm{RD}$, Baker ME, et al. Mechanisms of major biliary injury during laparoscopic cholecystectomy. Ann Surg 1992; 215: 196-202.

15 Moosa AR, Easter DW, Van Sonnenberg E, Casola G, D'Agostino $H$. Laparoscopic injuries to the bile duct: a cause for concern. Ann Surg 1992; 215: 203-8.

16 Kakos GS, Tompkins RK, Turnipseed W, Zollinger RM Operative cholangiography during routine cholecystecOperative cholangiography during
tomy. Arch Surg 1972; 104: 484-8.

17 Bailey RW, Zucker KA, Flowers JL, Scovill WA, Graham SM, Imbembo AL. Laparoscopic cholecystectomy. Experience with 375 consecutive patients. Ann Surg 1991 214: $531-41$.

18 Yip AWC, Ng WS, Chow WC, Choi TK, Lam KH. Plea for selective operative cholangiography. $\mathscr{f} R$ Coll Surg Edin 1991; 36: 21-4.

19 Pace BW, Cosgrove J, Breuer B, Margolis IB. Intraoperative cholangiography revisited. Arch Surg 1992; 127: 448-50.
20 McEntee G, Grace PA, Bouchier-Hayes D. Laparoscopic cholecystectomy and the common bile duct [Editorial]. Br F Surg 1991; 78: 385-6.

21 Vaira D, D'Anna L, Ainley C, Dowsett J, Williams S, Baillie J, Cairns S, et al. Endoscopic sphincterotomy in 1000 consecutive patients. Lancet 1989; ii: 431-4.

22 Gompertz RHK, Rhodes M, Lennard TWJL. Laparoscopic cholangiography: an effective and inexpensive technique. Br f Surg 1992; 79: 233-4.

23 Scott-Coombes D, Thompson JN. Bile duct stones and laparoscopic cholecystectomy [Editorial]. BMF 1991; 303: $1281-2$.

24 Crump C. The incidence of gall stones and gall-bladder disease. Surg Gynecol Obstet 1931; 53: 447-57.

25 Gerber A. A requiem for the routine operative cholangiogram [Editorial]. Surg Gynecol Obstet 1986; 163: 363-4.

26 Corder AP, Scott SD, Johnson CD. Place of routine operative cholangiography at cholecystectomy. Br $\mathcal{F}$ Surg 1992; 79: 945-7.

27 Pernthaler H, Sandbichler P, Schmid Th, Margreiter R. Operative cholangiography in elective cholecystectomy. Br F Surg 1990; 77: 399-400.

28 Voyles CR, Petro AB, Meena AL, Haick AJ, Koury AM. A practical approach to laparoscopic cholecystectomy. Am ₹ Surg 1991; 161: 365-70.

29 Grace PA, Qureshi A, Burke P, Leahy A, Brindley N, Osborne $\mathrm{H}$, et al. Selective cholangiography in laparoscopic cholecystectomy. Br $\mathcal{F}$ Surg 1993; 80: 244-6.

30 Acosta JM, Ledesma CL. Gallstone migration as a cause of acute pancreatitis. N Eng f Med 1974; 290: 484-7.

31 Kelly TR. Gallstone pancreatitis: pathophysiology. Surgery 1976; 80: 488-92.

32 Thurston OG, McDougall RM. The effect of hepatic bile on retained common duct stones. Sug Gynecol Obstet 1976; 143: 625-7.

33 Johnson AG, Hosking SW. Appraisal of the management of bile duct stones. $\mathrm{Br} \mathcal{F}$ Surg 1987; 74: 555-60.

34 Berci G, Sackier JM, Paz-Partlow M. Routine or selected intraoperative cholangiography during laparoscopic cholecystectomy. Am f Surg 1991; 161: 355-60.

35 Andrén-Sandberg A, Alinder G, Bengmark S. Accidental lesions of the common bile duct at cholecystectomy. Ann Surg 1985; 201: 328-332.

36 Cantwell DV. Routine cholangiography during laparoscopic cholecystectomy. Arch Surg 1992; 127: 483-4.

37 Alinder G, Nilsson U, Lunderquist A, Herlin P, Holmin T. Pre-operative infusion cholangiography compared to routine operative cholangiography at elective cholecystectomy. Br F Surg 1986; 73: 383-7.

38 Daly J, Fitzgerald T, Simpson CJ. Pre-operative intravenous cholangiography as an alternative to routine operative cholangiography in elective cholecystectomy. Clin Radiol 1987; 38: 161-3. 